\title{
Urinary N-telopeptide: The New Diagnostic Test for Osteoporosis
}

\author{
Ganesan Ram Ganesan, MS ${ }^{1}$ Phagal Varthi Vijayaraghavan, MCh ${ }^{1}$ \\ ${ }^{1}$ Department of Orthopaedics, Sri Ramachandra University, Chennai, \\ Tamil Nadu, India \\ Address for correspondence Ganesan Ram Ganesan, MS, Department \\ of Orthopaedics, Sri Ramachandra University, Ramachandra Nagar, \\ Chennai 600116, Tamil Nadu, India \\ Surg J 2019;5:e1-e4. \\ (e-mail: ganesangram@yahoo.com).
}

\begin{abstract}
Context Osteoporosis is a silent disease until it is complicated by trivial fall fractures. There is an increasing interest within the orthopaedic community in the noninvasive cost-effective measurement of the bone mineral density.

Aims The aim of the study is to assess whether urinary N-telopeptide level can be a new diagnostic tool in diagnosing osteoporosis.

Methods and Material This prospective study was done at Sri Ramachandra Medical Centre (SRMC) hospital from October 2015 to October 2017. The study was conducted among patients who comes to SRMC as inpatient or outpatient with suspected osteoporosis and underwent dual-energy X-ray absorptiometry (DXA) scan and urinary $\mathrm{N}$-telopeptide. The inclusion criteria were women aged 65 or older, women aged less than 65 with risk factors, younger postmenopausal women with one or more risk factors, men aged 70 or older, men less than 70 with risk factors, and any above group patients who comes within 24 hours following trivial fall fractures. The exclusion criteria were pathological fracture, history of any illness affecting bone metabolism. The results from DXA scan were taken as gold standard against urinary $\mathrm{N}$-telopeptide. Then the patients were divided into two groups control and study. The control group contains patients who had normal DXA, while study group contains patients having either osteopenia or osteoporosis. Based on our inclusion and exclusion criteria, 110 persons were included in the study. We had 60 study and 50 controls patients. We had 88 females and 22 males. The results obtained were statistically analyzed.

Statistical Analysis Used The collected data were analyzed with IBM SPSS statistics software 23.0 version. To describe about the data descriptive statistics frequency analysis, percentage analysis was used for categorical variables and the mean and standard deviation were used for continuous variables. To find the significant difference between the bivariate samples in independent groups, the unpaired sample $t$-test was used. To find the significance in categorical data, chi-square test was used. In both the earlier statistical tools, the probability value of 0.05 is considered as significant level. Results In our study, we had $18.2 \%$ osteopenic and $36.4 \%$ osteoporotic patients. The

\section{Keywords}

- osteoporosis

- DXA scan

- osteopenia

- telopeptide

- fracture mean value of urinary $\mathrm{N}$-telopeptide in control was 49.8 and in case was 182.5 . The standard deviation of urinary $\mathrm{N}$-telopeptide value in case was 159.9.

Conclusion Urinary $\mathrm{N}$-telopeptide can give reproducible results and be able to assist in the evaluation of the quantity as well as the quality and be a good judge of someone's risk of fracture. Hence, urinary N-telopeptide can be used as a diagnostic tool for diagnosing osteoporosis.
\end{abstract}

received

May 27, 2018 accepted after revision December 4, 2018
DOI https://doi.org/

10.1055/s-0038-1677483. ISSN 2378-5128.
Copyright $\odot 2019$ by Thieme Medical Publishers, Inc., 333 Seventh Avenue, New York, NY 10001, USA. Tel: +1(212) 584-4662.
License terms

(1) (1) 
Osteoporosis is a silent disease until it is complicated by trivial fall fractures. These fractures causes enormous financial, medical, and personal burden to the patients and to the nation. Osteoporosis not only affects woman but affects men also. Osteoporosis in men is underrecognized and thus undertreated. ${ }^{1}$ Till now, the gold standard for diagnosing osteoporosis is dual-energy X-ray absorptiometry (DXA) scan. DXA is a costly method to assess bone mineral density. Present scenario needs a simpler and more cost-effective method for diagnosing osteoporosis. There is an increasing interest within the orthopaedic community in the noninvasive cost-effective measurement of the bone mineral density. The aim of the study is to assess whether urinary N-telopeptide level can be a new diagnostic tool in diagnosing osteoporosis.

\section{Subjects and Methods}

This prospective study was done at Sri Ramachandra Medical Centre (SRMC) hospital from October 2015 to October 2017. The study was conducted among patients who comes to SRMC as inpatient or outpatient with suspected osteoporosis and underwent DXA scan and urinary N-telopeptide. The sampling method in this study is probability sampling. Ethics committee approval was obtained from SRMC institutional ethics committee. The inclusion criteria were women aged 65 or older, women aged less than 65 with risk factors, younger postmenopausal women with one or more risk factors, men aged 70 or older, men less than 70 with risk factors, and any earlier group patients who comes within 24 hours following trivial fall fractures. ${ }^{2-4}$ The exclusion criteria were pathological fracture, history of any illness affecting bone metabolism such as renal failure, hepatic failure, active malignancy, thyroid abnormalities, and drugs that affect bone metabolism such as steroids, anticonvulsants etc. The patients who meet the inclusion criteria were enrolled into the study. Prior informed consent was obtained from all patients.

DXA scan was done using GE healthcare Prodigy pro-DXA machine. DXA scan for right hip was done for all patients. If the patient is having fracture or operation done in the right hip, DXA scan was done in left hip or spine. In cases were DXA scan was done for hip and spine and any one area reported as normal and other as osteoporosis/osteopenia, then the patient was excluded from the study. Twenty-four hours urine was collected in a sterile plastic container. The collected specimen was sent to the centralized laboratory in SRMC. Urine sample was analyzed by enzyme-linked immunosorbent assay (ELISA) technique using Osteomark kit. The inter- and intra-assay coefficients of variation of Osteomark urinary N-telopeptide kit are 4.0 and $7.6 \%$, respectively.

The results from DXA scan were taken as gold standard against urinary $\mathrm{N}$-telopeptide. ${ }^{5,6}$ Then the patients were divided into two groups control and study. The control group contains patients who had normal DXA, while study group contains patients having either osteopenia or osteoporosis. Routine bone profile investigations such as serum calcium, phosphorus, alkaline phosphatase, serum albumin was done for all patients.
Based on our inclusion and exclusion criteria, 110 persons were included in the study. We had 60 study and 50 controls patients. We had 88 females and 22 males. The results obtained were statistically analyzed. The collected data were analyzed with IBM SPSS statistics software 23.0 version. To describe about the data descriptive statistics frequency analysis, percentage analysis was used for categorical variables, and the mean and standard deviation were used for continuous variables. To find the significant difference between the bivariate samples in independent groups, the unpaired sample $t$-test was used. To find the significance in categorical data, chi-square test was used. In both the earlier statistical tools, the probability value of 0.05 is considered as significant level.

\section{Results}

In our study, we had $18.2 \%$ osteopenic and $36.4 \%$ osteoporotic patients as evident from - Table 1. The mean value of urinary $\mathrm{N}$-telopeptide in control was 49.8 and in case was 182.5 . The standard deviation of urinary $\mathrm{N}$-telopeptide value in case was $\mathbf{1 5 9 . 9}$ from - Table 2. From - Table 3, the independent sample test for urinary N-telopeptide clearly shows significance association with osteoporosis/osteopenia. We had totally 53 patients associated with fracture out of which 47 were cases and 6 were controls.

\section{Discussion}

DXA scan will give us the quantity of bone; however, it does not give evaluation of patients bone quality. The factors that may alter or change the DXA scan results are artifacts, anatomy, machinery, location, varying technicians, and positioning of patients. Wherever there is radiation, there is always a chance of danger related to that. Any accidental exposure of radiation can cause drastic implications. However, if this is carefully done, the advantages of DXA outweigh its risk. Moreover, maximum permissible limit of precision error of technician doing DXA is around $1.7 \%$ for lumbar spine

Table 1 Results of DXA scan

\begin{tabular}{|l|l|l|l|}
\hline DXA scan & Study & Control & Percentage (\%) \\
\hline Normal & 0 & 50 & 45.5 \\
\hline Osteopenia & 20 & 0 & 18.2 \\
\hline Osteoporosis & 40 & 0 & 36.4 \\
\hline
\end{tabular}

Abbreviation: DXA, dual-energy X-ray absorptiometry.

Table 2 Mean values of urinary N-telopeptide

\begin{tabular}{|l|l|l|l|l|}
\hline Groups & $N$ & Mean & $\begin{array}{l}\text { Standard } \\
\text { deviation }\end{array}$ & $\begin{array}{l}\text { Standard } \\
\text { error mean }\end{array}$ \\
\hline Study & 60 & 182.540 & 159.968 & 20.6518 \\
\hline Control & 50 & 49.839 & 31.3343 & 4.4313 \\
\hline
\end{tabular}


Table 3 Independent sample test for NTx

\begin{tabular}{|l|l|l|l|l|l|l|l|l|l|}
\hline NTx value & \multicolumn{2}{l|}{$\begin{array}{l}\text { Levene's test for } \\
\text { equality of variances }\end{array}$} & \multicolumn{2}{l|}{ t-test for equality of means } \\
\cline { 2 - 9 } & $F$ & Significance & $T$ & $d f$ & $\begin{array}{l}\text { Significance } \\
\text { (two tailed) }\end{array}$ & $\begin{array}{l}\text { Mean } \\
\text { difference }\end{array}$ & $\begin{array}{l}\text { Standard } \\
\text { error } \\
\text { difference }\end{array}$ & $\begin{array}{l}\text { 95\% Confidence } \\
\text { interval of the } \\
\text { difference }\end{array}$ \\
\cline { 2 - 9 } & & & & & & & & & \\
Lower & Upper \\
\hline $\begin{array}{l}\text { Equal variance } \\
\text { assumed }\end{array}$ & 29.076 & 0.000 & 5.770 & 108 & 0.000 & 132.7006 & 22.9983 & 87.1140 & 178.2872 \\
\hline $\begin{array}{l}\text { Equal variances } \\
\text { not assumed }\end{array}$ & & & 6.283 & 64.394 & .0005 & 132.7006 & 21.1219 & 90.5097 & 174.8915 \\
\hline
\end{tabular}

and $1.3 \%$ for femoral neck. ${ }^{7}$ A major disadvantage of DXA is that currently, there is a lack of standardization in bone and soft tissue measurements. ${ }^{8}$ DXA scan reports tend to vary based on hydration status of patients, tissue thickness, and soft tissue composition in bony regions. It is evident that it is close to impossible to control all factors involved, and therefore, there are significant limitations to the current "gold standard." Immunoassays for biochemical markers of bone resorption were emerging that appear to be sufficiently specific and convenient for clinical use. ${ }^{10}$ The need for them arises because the impact of osteoporosis on the aging population increases and better tools to aid in risk prediction and prevention of osteoporosis was mandatory.

Bone resorption markers are important indicators of disease activity in patients with osteoporosis. Normalized results of these indicators are helpful in establishing the disease and its managements. Urinary N-telopeptide has been used for monitoring treatment for osteoporosis for a long time, but now, clinicians are using it to predict the onset of osteoporosis. The new ELISA immunoassay for the urinary excretion of cross-linked collagen peptides is a reliable and specific biochemical marker of bone resorption. ${ }^{11}$ The telopeptides are from Type I collagen which forms $90 \%$ of organic bone matrix and are cross-linked at $\mathrm{N}$ and $\mathrm{C}$ terminal ends of the molecules to form the basic fabric and tensile strength of the bone tissue. Urinary $\mathrm{N}$-telopeptide is a sensitive and specific marker of bone resorption. ${ }^{11}$ NTx is the stable degradation end product, which can be measured both in serum and urine. The NTx sequence is generated by osteoclastic activity and proteolysis. Hence it does not requires further breakdown or metabolism by kidney or liver for its production. ${ }^{12}$ Urinary N-telopeptide value does not significantly vary between male and female, and its range is pretty much same once the patient attains menopause. The urinary excretion is not affected by diet, and therefore shows less variation than the conventional markers. ${ }^{13}$

From - Table 3, the independent sample test for urinary $\mathrm{N}$-telopeptide clearly shows significance association with osteoporosis/osteopenia. There is statistical significance of urinary $\mathrm{N}$-telopeptide in study group when compared with the control considering DXA scan as a gold standard. Similarly, urinary $\mathrm{N}$-telopeptide values are significantly higher in the patients who had an associated fracture. The implication from - Tables $\mathbf{4}$ and $\mathbf{5}$ is that fracture is more common in the patients having osteoporosis/osteopenia. Chi-square test for fracture association in the study group is also statistically significant. Serum calcium, serum phosphorus, and serum alkaline phosphatase did not show significant correlation with urinary N-telopeptide value between study and control groups.

The N-telopeptide is specific to bone due to its unique amino acid sequence. Bone density as measured by DXA provides a static snapshot of bones and does not distinguish if bone loss is ongoing or not. But urinary N-telopeptide is a dynamic measurement of what is actually happening in bone at any given time. There is considerable research ongoing to find a better study to replace the DXA scan. Considering financial parts of the investigations urinary $\mathrm{N}$-telopeptide assessment is being cheaper than DXA. The cost of single region DXA scan is around 2,500 rupees, while urinary $\mathrm{N}$ -

Table 4 Study group patients association with fracture

\begin{tabular}{|c|c|c|c|c|c|}
\hline & & & \multicolumn{2}{|l|}{ Groups } & \multirow[t]{2}{*}{ Total } \\
\hline & & & Study & Controls & \\
\hline \multirow[t]{4}{*}{ Associated with fracture } & \multirow[t]{2}{*}{ No } & Count & 13 & 44 & 57 \\
\hline & & \% Within groups & $21.7 \%$ & $88.0 \%$ & $51.8 \%$ \\
\hline & \multirow[t]{2}{*}{ Yes } & Count & 47 & 6 & 53 \\
\hline & & \% Within groups & $78.3 \%$ & $12.0 \%$ & $48.2 \%$ \\
\hline \multirow{2}{*}{\multicolumn{2}{|c|}{ Total }} & Count & 60 & 50 & 110 \\
\hline & & \% Within groups & $100.0 \%$ & $100.0 \%$ & $100.0 \%$ \\
\hline
\end{tabular}


Table 5 Chi-square test for fracture association with study group

\begin{tabular}{|l|l|l|l|l|l|}
\hline & Value & $d f$ & $\begin{array}{l}\text { Asymptotic } \\
\text { significance } \\
\text { (two sided) }\end{array}$ & $\begin{array}{l}\text { Exact significance } \\
\text { (two sided) }\end{array}$ & $\begin{array}{l}\text { Exact significance } \\
\text { (one sided) }\end{array}$ \\
\hline Pearson chi-square & 48.065 & 1 & 0.0005 & & \\
\hline Continuity correction & 45.445 & 1 & 0.000 & & \\
\hline Likelihood ratio & 52.936 & 1 & 0.000 & & 0.000 \\
\hline Fisher's exact test & & & & & \\
\hline$N$ of valid cases & 110 & & & & \\
\hline
\end{tabular}

telopeptide ELISA kit is around 25,000 rupees for 100 patients. If urinary $\mathrm{N}$-telopeptide test were done more frequently, then the kit can be purchased in a much cheaper rate. Moreover, cost of installing DXA, maintaining, and dayto-day running were enormously high compared with a simple urine test such as N-telopeptide. As urinary N-telopeptide is cheap, it can be considered as a screening test also. If we suspect osteoporosis, it is better to go for urinary Ntelopeptide and those who test positive can go for current gold standard DXA scan. Thus, combination of these two diagnostic tests could be useful to improve the identification of high risk for fracture.

\section{Conclusion}

Urinary N-telopeptide can give reproducible results and be able to assist in the evaluation of quality of bone and osteoporosis and be a good judge of someone's risk of fracture. Hence, urinary N-telopeptide can be considered as a new diagnostic tool for diagnosing osteoporosis.

\section{Conflict of Interest}

None.

\section{References}

1 Shepherd AJ, Cass AR, Carlson CA, Ray L. Development and internal validation of the male osteoporosis risk estimation score. Ann Fam Med 2007;5(06):540-546

2 Cianferotti L, Brandi ML. Guidance for the diagnosis, prevention and therapy of osteoporosis in Italy. Clin Cases Miner Bone Metab 2012;9(03):170-178
3 Cummings SR, Black DM, Rubin SM. Lifetime risks of hip, Colles', or vertebral fracture and coronary heart disease among white postmenopausal women. Arch Intern Med 1989;149(11):2445-2448

4 Riggs BL, Melton LJ III. Involutional osteoporosis. N Engl J Med 1986;314(26):1676-1686

5 Punda M, Grazio S. Bone densitometry-the gold standard for diagnosis of osteoporosis [in Croatian]. Reumatizam 2014;61 (02):70-74

6 Schneider DL, Barrett-Connor EL. Urinary N-telopeptide levels discriminate normal, osteopenic, and osteoporotic bone mineral density. Arch Intern Med 1997;157(11):1241-1245

7 Sievänen H, Oja P, Vuori I. Precision of dual-energy x-ray absorptiometry in determining bone mineral density and content of various skeletal sites. J Nucl Med 1992;33(06):1137-1142

8 Institute of Medicine (US) Committee on Military Nutrition Research. Carlson-Newberry SJ, Costello RB, eds. Emerging Technologies for Nutrition Research: Potential for Assessing Military Performance Capability. Washington, DC: National Academies Press (US); 1997. 6, Dual-Energy X-Ray Absorptiometry: Research Issues and Equipment. Available at: https://www.ncbi.nlm.nih. gov/books/NBK233779/. Accessed January 2, 2019

9 Rothney MP, Brychta RJ, Schaefer EV, Chen KY, Skarulis MC. Body composition measured by dual-energy X-ray absorptiometry half-body scans in obese adults. Obesity (Silver Spring) 2009;17 (06):1281-1286

10 Kleerekoper M, Edelson GW. Biochemical studies in the evaluation and management of osteoporosis: current status and future prospects. Endocr Pract 1996;2(01):13-19

11 Jayaram N, Bijoor AR, Rajagopalan N, Venkatesh T. The value of serum and urinary n-telopeptide in the diagnosis of osteoporosis. Indian J Orthop 2002;36:9-13

12 Singer FR, Eyre DR. Using biochemical markers of bone turnover in clinical practice. Cleve Clin J Med 2008;75(10):739-750

13 Bettica P, Moro L, Robins SP, et al. Bone-resorption markers galactosyl hydroxylysine, pyridinium crosslinks, and hydroxyproline compared. Clin Chem 1992;38(11):2313-2318 